\author{
ANALYSIS OF THE DISCUSSION PAPER "THE CARE OF THE PATIENT AND THE SOUL \\ OF THE CLINIC: PERSON-CENTERED MEDICINE AS AN EMERGENT MODEL OF \\ MODERN CLINICAL PRACTICE" BY ANDREW MILES AND JUAN E. MEZZICH, IJPCM \\ 2011; 1 (2) 207-222
}

\title{
What Person-Centered Medicine is and isn't: Temptations for the 'soul' of PCM
}

\author{
Michael Loughlin PhD \\ Reader in Applied Philosophy, Manchester Metropolitan University, Crewe, Cheshire, UK
}

\section{Correspondence address}

Dr. Michael Loughlin, Department of Interdisciplinary Studies, Manchester Metropolitan University, Crewe, Cheshire, CW1 5DU, UK. E-mail: m.loughlin@mmu.ac.uk

Accepted for publication: 21 August 2012

\section{Introduction}

In their important discussion paper presenting personcentred medicine (PCM) as 'an emergent model of modern clinical practice' [1], Miles and Mezzich note a rather obvious comparison between the rhetoric of their own favoured 'model' and the rhetoric of the evidence-based medicine (EBM) movement. For all their differences, PCM and EBM have something in common. While we may disagree about what evidence is or indeed just not be sure what it is, we are generally agreed that we are in favour of it. A movement that is all about promoting the use of evidence in medicine sounds about as uncontroversial as it gets. I might be oblivious to scientific debates about the nature of evidence and have no idea how to define the term, but I know that I want anyone treating me to use evidence, all the same. I may wonder what else medical decisions should be based on, if not evidence? [2]. Similarly, it would make very little sense to be 'against' persons. I may have never given a moment's thought to philosophical disputes about the nature of persons, but I know that however one defines persons, I am one of them and in reply to the question: 'Should medicine care for persons or not?' few would answer in the negative. Again, I might wonder: if medicine is not about caring for 'the person', then what is it about?

Miles and Mezzich are therefore quite right to worry that 'the nomenclature of "person-centred medicine' risks the accusation that such a term represents a 'further rhetorical addition to the already rhetorically overburdened nature of health services' [1]. Practitioners struggling to do their jobs in the resource-constrained environments of contemporary health services may well react cynically to the latest linguistic innovation, especially if it seems, like its predecessors, to combine the blindingly obvious with the 'revolutionary' [3]. People are rightly suspicious of any movement, model, approach or paradigm, that purports to have the potential to improve practices in some substantial way, but is at the same time apparently founded on claims that fail what Charlton has called 'the platitude test' [4].

Insofar as there is a legitimate worry here, it is worth being very clear about what that worry is. The problem with evidence-based medicine was not that the term 'evidence' is contested. Of course it is and it is right that its proper meaning and application in a range of medical contexts will continue to be debated, whether in future we talk about evidence-based medicine or, as Miles and Mezzich recommend, evidence-informed medicine. The problem was with the use made of the rhetorical properties of the term by prominent figures in the EBM movement. Despite repeated allusions to the 'evolution' of the debate in the EBM literature [5-8], key contributors from the outset had little time for the idea of an on-going process of intellectual evolution [9-11], preferring instead to declare their own work the 'dawn' of a new 'era', a radical break with the past and a dramatic conceptual 'shift' [12]. Authors sought to speak definitively on the nature of evidence, to set a new 'standard' [13] and the whole point of the language lifted from Kuhn [14] of 'paradigm shifts' and 'scientific revolutions' [12,13] was, precisely, to emphasise the lack of scope for any meaningful dialogue between EBM's understanding of 'evidence' and ideas derived in the dark era of 'traditional medicine', prior to the EBM dawn. The notion that reasonable people might disagree, significantly, about the nature of evidence, was one that never really took hold within the EBM community.

So the problem with EBM was the implicit denial of the contested nature of its key term, 'evidence'. Critics were assumed to have misunderstood, which is why responses to academic criticism took the form not of counter-argument, but of 'clarification' [15]. The famous explanation of what EBM 'is and isn't' presented by Sackett and colleagues ('the conscientious, explicit and judicious use of current best evidence in making decisions about the care of individual patients') was platitudinous, but the problem with the paper was that it traded on the 
platitudinous nature of that explanation, while clearly, at the same time, assuming a more substantive conception of 'evidence' and maintaining that, in some semantically significant sense, all medicine should be 'based on' that account of evidence. When these authors (and authors who followed them $[5-8,16])$ proceeded as though their contested claims about the nature and role of evidence in medicine were somehow vindicated, simply by repeated association with platitudes, they committed a rhetorical fallacy, affecting a position at once platitudinous (such that no reasonable disagreement with it is possible) and substantial ('radical', 'revolutionary', etc.). Effectively, they claimed 'ownership' of the language of 'medical evidence', treating a once common term (open to a range of legitimate interpretations) as a technical term, which EBM authors had the authority to define stipulatively thus rendering any further debate about its meaning superfluous [17]. The success of this rhetorical enterprise is in part confirmed by the fact that such astute critics of EBM as Tonelli elected not to contest the meaning of the term 'evidence', in effect 'giving it up' to the EBM camp, preferring instead to dispute the dominance of EBM by speaking of non-evidential warrants for clinical decisionmaking $[18,19]$. Indeed, for much of the time, when Miles and Mezzich speak of 'evidence', they mean what they call 'the E of EBM' and this is why the shift from 'evidencebased' to 'evidence-informed' medicine is important for them [1].

Logically similar rhetorical strategies can be found in the literature on the application of management and organisational theory to healthcare and education [20-22] and also in some of the more 'applied' work in the field of bioethics [22-24]. Authors in these areas routinely and swiftly moved from assertions about the desirability of 'organisational quality' and 'a rigorous commitment to promoting ethical practice' (ideas no-one could seriously dispute) to deeply contentious claims about the desirability of greater control of professional practice by monitoring agencies, line-management structures and regulatory ethics committees. Ironically and, I think worryingly, those authors willing to commit what any first year logic student would recognise as a basic fallacy (treating a contentious thesis as though it follows deductively from a platitude or set of platitudes) have often been rewarded in professional terms, in that their work has had an 'impact' on the thinking of policymakers [20-22] - that section of the population most in the market for 'miracle cures' for our social, organisational and professional ills (or rather, for something they can present as a miracle cure). As I have noted elsewhere, pointing out that overworked practitioners need more time off and more support, is unlikely to further the career of an ambitious researcher. On the other hand: '[a]n insight at once so radical as to require a revolution in practice and so just-plain-obvious as to require no defence might sound too good to be true, but to politicians searching for a "big idea", it is just the ticket' [3]. In terms of their real methodologies, 'quality management' and evidence-based medicine have virtually nothing in common, but they were both (simultaneously) heralded in government literature as key components or 'central planks' of UK health policy [25,26]. Arguably, their appeal had much to do with the little they do have in common - a willingness on the part of their protagonists to abuse the rhetorical properties of their defining terms, to produce 'solutions' that can be defended with reference to a few, rhetorically appealing phrases, but which at the same time can be presented as having 'ground-breaking' implications for policy and practice $[17,20]$.

\section{Implic ations for person-centred medicine}

The worry for PCM, then, is that the rhetorical properties of its defining terms present authors in the field with the sorts of temptation to which protagonists of the approaches mentioned above typically and all too readily succumbed. Following Peabody [27], Miles and Mezzich [1] explicate PCM with reference to the 'soul' of the clinic. For the ancients, one common use of 'soul' (or 'form') was to identify that which gave a person or organism integrity, the holding together of components of the whole in balance, to sustain proper functioning [28]. In this sense, there are two ways that PCM can lose its 'soul' and the challenge for PCM as the debate about its nature and direction develops will be to maintain a proper balance between these two tempting, but destructive extremes.

On the one hand, focussing on the general, 'every day' meaning of the term 'person', 1 provides an easy way to explain to workers and policymakers too 'busy' to listen to any 'intellectual ruminations' $[7,11]$, that one is not saying anything fundamentally incompatible with whatever they believe already and indeed the proposition that medicine should be 'person-centred' is so straightforward as to be virtually self-evident. The price paid for such automatic plausibility is a high one: it leaves PCM too vague a doctrine to be of any practical use. It allows the claim that medicine should be person-centred to mean just whatever the listener already takes it to mean, making it too subjective an idea to determine any specific conclusions for policy and practice.

To resist this temptation, authors might be tempted instead to issue some definitive statements to explain what PCM means, to 'clarify' what PCM 'is and isn't'. The problem here is the risk of laying down the law about what is, in fact, rightly, a contested matter. The meaning of 'person' and related concepts has by no means been 'settled', nor is there a broad consensus regarding what, precisely, it means to say that 'the person' should be at the 'centre' of medicine. The tendency to appropriate terms from common discourse and treat them as technical terms, defined authoritatively within one's own specific theoretical frame, is a common one for academics. Throughout this paper, I have treated the plural of 'person' not as the more usual 'people', but as 'persons', a term

\footnotetext{
${ }^{1}$ The one that would enable Richard Dawkins and The Pope, despite their philosophical differences, to agree that they needed two dinner passes between them, in the unlikely event of their attending the same conference and being told that the organisers allocated 'one pass per person'.
} 
found more often in philosophical discussions of 'personhood', without (until now!), even noting or noticing that there is a difference.

The most serious threat to the 'soul' of PCM is the possibility of giving way to both temptations at once, to combine (perhaps even in the course of the same paper) both extremes with shameless inconsistency, to insist on employing both the self-evident and some quite specific, technical meaning of 'person-centred', while refusing to recognise any distinction worth mentioning between them. This was the path chosen by the protagonists of management theory and EBM and, as noted, it can yield professional rewards. (That is, one assumes, what makes it such a serious temptation). By giving the impression that one has (yet another) miraculous combination of the revolutionary and the blindingly obvious, one supplies what many policymakers understand by a theory with 'practical applications' [20]. That way lies impact and perhaps further funding $[3,4]$. What, then, is the virtuous alternative, the way for contributors to this debate to say something 'at once true and helpful' [22], while recognising and avoiding the dangers inherent in the project?

The more difficult middle ground lies in recognising the nature and limitations of the contribution that theoretical approaches can make to practice and the importance of fostering an on-going, intellectually serious debate about practice that involves all concerned - most notably practitioners and patients. To me, the most important contribution of Miles and Mezzich [1,29] and other contributors to this area [30-35], lies not in their specific conclusions, but in their relentless determination to remind us that, despite the triumphalism of earlier academic movements, the underlying and typically naïve questions about what medicine is all about have not been resolved. We need to revisit these underlying questions about the purpose and value of medical interventions, the nature of the clinical encounter and medical knowledge which frame our thinking about practice, precisely to avoid their becoming effectively (and arbitrarily) settled by default.

At the moment, PCM seems to be defined at least as much by what it rejects as by what it proposes. Certainly, Miles and Mezzich from the outset explain PCM as, in no small part, a reaction to conceptions of practice influenced too heavily by reductionist accounts of the person and the sort of narrow scientism that threatens to reduce both professional judgement and patient care to forms of technocratic 'know-how' [1]. Some will treat this as a weakness, thinking that 'negativity' is always a bad thing and only 'positive proposals' are valuable. In fact, it is crucially important for any intellectually serious proposal to be clear about what it rules out and 'negative' contributions to an on-going debate are every bit as important as 'positive' ones [22]. That is the whole point of Charlton's platitude test: to say what something means you need to be able to say what it denies, as a proposal compatible with everything in fact asserts nothing [4]. (Whatever the problems with the logical positivist movement, this particular insight - that a claim which denies nothing typically asserts nothing - is one that the work of positivists such as the early Ayer [36] very much impressed upon our intellectual culture and for that they deserve much credit). There is also, in the writings of Miles and Mezzich [1,29], as well as other authors in this area [31,37-40], more than a hint of a return of virtue ethics, the desire to revive a serious conception of wisdom as at the heart of professional practice and the idea that we need to rethink certain 'modern' dichotomies, including the distinction between 'reason' and 'emotion': a truly rational human being is a well-balanced person, with empathic and other emotional capacities being essential components of human rationality.

All of these ideas are important and indicative of a desire to reframe our thinking about medical practice and to revive aspects of thinking and practice that are in danger of being lost in the current environment. But we should not aim to resolve decisively what PCM implies for practice. We should accept that distinct and even incompatible ideas about persons, virtue, professional judgement, patient autonomy and the relationship between individuals and the community, will be entertained by people who can all, nonetheless, have a legitimate claim to characterise their thinking in terms of the language of person-centred medicine. It is not a language that anyone should come to 'own'.

Will this not make PCM too subjective, in the sense I was worrying about earlier in the paper? Not necessarily. There is an important distinction between an idea that is 'subjective', in a sense that implies it can mean anything you like and its being 'contested' in a way that implies not only that reasonable people disagree about what it means, but also that they are likely to disagree for the foreseeable future. There is, in fact, nothing wrong with noting the centrality of both evidence and persons in any defensible account of medical practice, so long as one acknowledges that these ideas are contested. The danger arises when, in the desire to be seen to say something substantive and practical, one then lays down the law about what a term must mean, ruling out, without adequate argument, alternative conceptions to one's own. This sort of linguistic legislation aims to bring an abrupt end to intellectual debate, to declare that, for the subject matter at hand, intellectual history has now reached its resolution, that it has come to an end. Far from bringing advances, this tendency stifles real debate, reducing every discussion to a debate about 'how-to' apply certain techniques in practice.

We do need a serious interrogation, not only of the crucial idea of 'persons', but also of what precisely it means to claim that medicine should be 'centred' on persons. In what follows, I will say something about the specific claims of Miles and Mezzich on these points, not with a desire to resolve the issues, but in the hope of raising some questions and objections that might further the debate.

\section{A Hegelian synthesis?}

Miles and Mezzich propose that PCM is a Hegelian synthesis of EBM and Patient Centred Care (PCC) [1]. 
This follows earlier claims [41] that we are at a 'Hegelian moment' in the history of the debate about medical epistemology and ethics. In contrast to the language of a paradigm shift, which (as noted above) emphasises the lack of continuity and dialogue between what one is proposing and what has gone before, this Hegelian terminology suggests continuity and development, an approach somehow growing out of what has gone before in the course of intellectual exchange and progress. As defenders of EBM are finally beginning to engage in serious dialogue with those from outside the EBM camp [42,43] and as some are preferentially using the language of 'evidenceinformed' as opposed to 'evidence-based' medicine (a language traditional opponents of EBM are much happier to accept and with good reason $[1,41]$ ), it is right to look for ways to combine the insights of previously opposed approaches. As a co-author of an editorial calling for a 'Hegelian moment', I have no objection to the general idea of a synthesis between previously distinct traditions:

\begin{abstract}
'That is to say, we are at a point in the history of medicine when insights from approaches that have, historically, been set up in opposition to each other (the focus on improving the science of medicine and the focus on medicine as a caring, human, occupation, whose practitioners and patients are persons, with all this entails) might be fully reconciled. Rather than subordinating one approach to the other, rather than privileging one side of the picture and then puzzling over how to re-integrate the other, we look forward to the proper synthesis of these approaches. The challenge of medical humanities is as intellectually serious and practically urgent as medical science and we look forward to the development of accounts of medicine that do full justice to its human and social complexity, drawing on the full range of sources that form our intellectual heritage - in science, ethics, philosophy and allied humanities.' [41]
\end{abstract}

I am, however, a little more cautious about presenting PCM as the product of a synthesis between the specific doctrines designated by the initials EBM and PCC, respectively. One of the things its advocates hope PCM will do (and this is evident in a number of places in the Miles \& Mezzich discussion paper [1]) is to defend the idea of the clinician as a person being entitled to use her/his professional expertise and outlook to make judgements - of course, informed by the evidence and in dialogue with the judgements of the patient (where 'judgements' reflect both a person's broad background assumptions and world-view as well as more clearly subjective, but potentially extremely important things such as preferences). The crucial idea expressed by Henry that 'the clinical encounter is an interaction between persons' [34], requires that both parties have something distinctive to bring and, in particular, that the professional is not reduced to the role of one delivering a 'product' to requirements drawn up by the patient as a 'consumer' of care.

Miles and Mezzich reference Berwick [1,44] as a representative of PCC. This author was previously a contributor to the quality management debate $[22,45]$ and as Meaghre notes [46], he advances what is very much a 'consumerist' model of the patient-professional relationship. Miles and Mezzich recognise this aspect of the PCC literature when they note that they, in contrast to proponents of PCC, do not recognise the obligation to care for patients 'on their own terms', with 'a clinician as a simple provider of goods' [1]. Arguably, and despite being 'poles apart' in the ways Miles and Mezzich bring out, EBM and PCC both won support from policymakers, at least in part because they helped to contribute to an antiprofessional agenda that was part and parcel of the 'managerial revolution' [20-22]. Some of the work on PCC (including Berwick's [44]) resonates with all the literature about championing the service-user against the dominance of professionals, while EBM relegates 'expert opinion' to a form of low-grade evidence and treats the need for professional judgement as indicative of a regrettable lack of evidence [39]. Looked at in that way, it is harder to work out how either position contains the potential, when merged with the other, to give rise to a re-introduction of a strong sense of the value of professional judgement and of the inescapability of judgement.

So the portrayal of PCM as the synthesis of PCC and EBM, though extremely appealing, looks a bit too neat to me to represent the real nature of these distinct positions. Rather, what we are looking for is a synthesis of the sciences and the humanities in medicine, an end to the futile and tedious insistence that these aspects are fundamentally opposed, that medicine is 'really' a science, but with a human side, rather than a human activity that employs insights from a wide range of disciplines in the cause of promoting the human good.

\section{The human animal and political animals}

The debate about the nature of the person in philosophy spans the philosophy of mind and action, ethics and political philosophy and, if PCM is to avoid providing 'quick fix' solutions and to encourage, instead, an intellectually serious debate about the fundamental questions facing medicine, then it cannot altogether avoid these areas. Miles and Mezzich state that the patient is a person 'because he has personhood which, as Schaffner has argued, signifies human agency in all levels of being and in all contexts' [29]. This model of a person needs a good deal more attention than can be given here, but it sounds like quite a demanding criterion of personhood and, as a general rule, the harder it is to satisfy the paradigm of a 'person' being employed, the more defenders of PCM are going to have to qualify what they mean by 'centred'. I do not believe Miles and Mezzich would want to see medical interventions restricted to 'persons' in any strong sense, as this would suggest that human subjects falling short of the model of 'personhood' in some way would fall outside the scope of legitimate medical concern. Would they be happy to see those humans with diminished agency, referred to by some philosophers as 'marginal cases' [47], relegated to the margins of medical concern (one possible reading of the claims that 'persons' are essentially 'agents' and that they should be the 'centre' of medicine)? I am certain that 
they would not, but this suggests that greater clarification of the implications of the key terminology of 'personcentredness' is still needed.

The authors may be happy to endorse Peabody's claim that 'disease in man is never the same as disease in an experimental animal, because in man disease at once affects and is affected by what we call the emotional life' [48]. While Peabody has an important point about the way the experience of disease influences and is influenced by the specific conditions of an individual's life, I see no need for PCM to commit itself to any highly controversial thesis to the effect that there is an absolute cognitive and affective divide between human creatures and the animals from which they evolved. There is nothing particularly 'scientific' about such a belief [49,50], nor is there anything resembling a philosophical consensus on the capacities of non-human animals to experience distress, anxiety, empathy and other emotions [50-53]. Indeed, it is arguable that we possess some of our distinctively human features because we are mammals of a certain sort [49,50,53-55] and some recent challenges to scientism have stressed the biological side to human rationality as part of an account of what is missing from the unduly abstract views of human reasoning and knowledge found in reductionist accounts of the human animal [39,49,5355].

\section{Conclusion}

Miles and Mezzich certainly recognise that no model of 'personhood' can be both substantive and politically neutral, such that a full account of PCM will make reference to how we conceive of our rights and duties in the context of a broader social order that delimits the scope and provides the resources for medical interventions $[1,29]$. This supplies another reason to stress the contested nature of PCM, as it would be bizarre indeed to hope for a broad political consensus shared by all who may have a legitimate claim to characterise their thinking in terms of the language of person-centred medicine. As the discourse develops, we may well see different versions of PCM emerging, influenced by alternative communitarian and individualist approaches to personhood and this will at least help to make more transparent the relationship between our background assumptions and the conclusions we draw about resource allocation and value in healthcare - assumptions too often disguised by pseudo-scientific devices to quantify value and 'rationalise' the processes of resource allocation [22].

I must admit to having some concerns about the authors' keenness to stress the potential for PCM to cut costs $[1,29]$. While no-one wants to waste vital health resources (again, apply the platitude test), one hope for PCM is that it might be that it causes us to reconsider how we employ the evaluative concept of 'waste' in a range of areas. As well as reassuring policymakers that the approach need not require an increase in health expenditure, we may also offer a model to service users and practitioners that enables them to explain the contribution their services make to human flourishing (to employ an 'outdated' term in urgent need of revival [55]) and indeed to challenge the social order in which they operate to explain its priorities with reference to its concern for the value of the persons who make up its body politic. What PCM means and what it might represent in future, are still very much 'up for grabs' at this stage of the debate.

\section{Conflicts of Interest}

The author declares no conflict of interest.

\section{References}

[1] Miles, A. \& Mezzich, J.E. (2011). The care of the patient and the soul of the clinic: person-centred medicine as an emergent model of modern clinical practice. International Journal of Person Centered Medicine 1 (2) 217-222.

[2] Worrall, J. (2010). Evidence: philosophy of science meets medicine. Journal of Evaluation in Clinical Practice 16 (2) 356-362.

[3] Loughlin, M. (2010). Spin-doctors. The Philosopher's Magazine 51 (4) 68-73.

[4] Charlton, B.G. (1996). The limits of evidence-based medicine. Hospital Update July, 268-269.

[5] Djulbegovic, B., Guyatt, G.H. \& Ashcroft, R.E. (2009). Epistemologic inquiries in evidence-based medicine. Cancer Control 16 (2) 158-168.

[6] Goodman, K. (2003). Ethics and Evidence-Based Medicine: Fallibility and Responsibility in Clinical Science. Cambridge: Cambridge University Press.

[7] Dans, A., Dans, L. \& Silverstre, M. (2008). Painless Evidence-based Medicine. Chichester:Wiley.

[8] Jenicek, M. (2006). Evidence-based medicine: fifteen years later. Golem the good, the bad and the ugly in need of a review? Medical Science Monitor 12, 241-251.

[9] Loughlin, M. (2009). The search for substance: a quest for the identity-conditions of evidence-based medicine and some comments on Djulbegovic et al. Journal of Evaluation in Clinical Practice 15 (6) 910-914.

[10] Miles, A., Loughlin, M. \& Polychronis, A. (2008). Editorial Introduction and Commentary: 'Evidence-based health care, clinical knowledge and the rise of personalised medicine'. Journal of Evaluation in Clinical Practice 14 (5) 621-649.

[11] Loughlin, M. (2009). The basis of medical knowledge: judgement, objectivity and the history of ideas. Journal of Evaluation in Clinical Practice 15 (6) 935-940.

[12] Evidence-Based Medicine Working Group. (1992). Evidence-based Medicine: a new approach to teaching the practice of medicine. Journal of the American Medical Association 268 (17) 2420-2425.

[13] Davidoff, F., Haynes, B., Sackett, D. \& Smith, R. (1995). Evidence-based medicine. British Medical Journal 310, 10851086.

[14] Kuhn, T.S. (1970). The Structure of Scientific Revolutions, 2nd Edition. Chicago: University of Chicago Press.

[15] Sackett, D.L., Rosenberg, W.M.C., Muir Gray, J.A., Haynes, R.B. \& Richardson, W.S. (1996). Evidence-based 
medicine: what it is and what it isn't. British Medical Journal 312, 71-72.

[16] Goldacre, B. (2006). Objectionable 'objectives'. The Guardian August 19.

[17] Loughlin, M. (2007). Style, Substance, Newspeak 'and all that': a commentary on Murray et al. (2007) and an open challenge to Goldacre and other 'offended' apologists for EBM. Journal of Evaluation in Clinical Practice 13 (4) 517521.

[18] Tonelli, M. (2006). Integrating evidence into clinical practice: an alternative to evidence-based approaches Journal of Evaluation in Clinical Practice 12 (3) 248-256.

[19] Loughlin, M. (2006). The future for medical epistemology? Commentary on Tonelli's 'Integrating evidence into clinical practice: an alternative to evidencebased approaches'. Journal of Evaluation in Clinical Practice 12 (3) 289-291.

[20] Loughlin, M. (2002). On the buzzword approach to policy formation, Journal of Evaluation in Clinical Practice 8 (2) 229-242.

[21] Loughlin, M. (2004). Quality, Control and Complicity, International Journal of the Humanities 2, 717-724.

[22] Loughlin, M. (2002). Ethics, Management and Mythology. Oxford: Radcliffe Medical Press.

[23] Loughlin, M. (2002). Arguments at cross purposes: moral epistemology and medical ethics. Journal of Medical Ethics 28 (1) 28-32.

[24] Loughlin, M. (2003). Critical thinking versus moral expertise: a commentary on Kottow's 'rationale for valueladen medicine'. Journal of Evaluation in Clinical Practice 9 (1) 92-94.

[25] Halligan, A. \& Donaldson, L. (2001). Implementing clinical governance: turning vision into reality. British Medical Journal 322, 1413-1417.

[26] Halligan, A., Nicholls, S. \& O’Neill, S. (2001). Clinical Governance: developing organisational capability. In: Clinical Governance and the NHS Reforms, pp. 129-154. Miles, A., Hill, A. \& Hurwitz, B. (eds.). London: Aesculapius Medical Press.

[27] Peabody, F.W. (1928). The soul of the clinic. Journal of the American Medical Association 90, 1193-1197.

[28] Sorabji, R. (1983). Time, Creation and the Continuum. London: Duckworth.

[29] Miles, A. \& Mezzich, J.E. (2011). Person-centred medicine: advancing methods, promoting implementation. International Journal of Person Centred Medicine 1 (3) 423428.

[30] Cox, J. (2010). Medicine of the Person and Personalised Care. Journal of Evaluation in Clinical Practice 16 (2) 315317.

[31] Gelhaus, P. (2011). I, Medical Robot: On the differences between a virtuous doctor and a good robot. International Journal of Person Centred Medicine 1 (2) 301-306.

[32] Walsh, B. \& Gillett, G. (2011). Is evidence-based medicine positivist? International Journal of Person Centered Medicine 1 (2) 323-329.

[33] Little, M., Gordon, G., Markham, P., Lipwort, W. \& Kerridge, I. (2011). Making decisions in mechanistic, probabilistic and scientific domains of medicine: a qualitative study of medical practitioners. International Journal of Person Centered Medicine 1 (2) 376-384.

[34] Henry, S. (2010). Polanyi's tacit knowledge and the relevance of epistemology to clinical medicine. Journal of Evaluation in Clinical Practice 16 (2) 292-297.
[35] Macnaughton, J. (2011). Medical humanities' challenge to medicine. Journal of Evaluation in Clinical Practice 17 (5) 927-932.

[36] Ayer, A.J. (1987). Language, Truth and Logic. Harmondsworth, Middlesex: Penguin Books Ltd.

[37] Gelhaus, P. (2011). Robot Decisions: the importance of virtuous judgement in clinical decision-making. Journal of Evaluation in Clinical Practice 17 (5) 833-837.

[38] Marcum, J. (2011). The role of prudent love in the practice of clinical medicine. Journal of Evaluation in Clinical Practice 17 (5) 877-882.

[39] Loughlin, M. (2008). Reason, reality and objectivity: shared dogmas in the way both scientistic and postmodern commentators frame the EBM debate. Journal of Evaluation in Clinical Practice 14 (5) 665-671.

[40] Loughlin, M., Bluhm, R., Buetow, S., Goldenberg, M., Upshur, R., Borgerson, K. \& Entwistle, V. (2011). Virtue, Progress and Practice. Journal of Evaluation in Clinical Practice 17 (5) 839-846.

[41] Miles, A. \& Loughlin, M. (2011). Models in the balance: evidence-based medicine versus evidence-informed individualized care. Journal of Evaluation in Clinical Practice 17 (4) 531-536.

[42] Howick, J. (2011). The Philosophy of Evidence-Based Medicine. Chichester: Wiley-Blackwell.

[43] Tonelli, M. (2011). The philosophy of evidence-based medicine by Jeremy Howick. Journal of Evaluation in Clinical Practice 17 (5) 1013-1017.

[44] Berwick, D.M. (2009). What 'patient centred' should mean: confessions of an extremist. Health Affairs 28, 555556.

[45] Berwick, D.M. (1993). Continuous Improvement as an Ideal in Health Care. In: The Textbook of Total Quality in Healthcare, pp. 31-39. Al-Assaf \& Schmele (eds.). Delray Beach Florida: St Lucie Press.

[46] Meagher, K. (2011). Considering virtue: public health and clinical ethics. Journal of Evaluation in Clinical Practice 17 (5) 888-893.

[47] Frey, R. (1980). Interests and Rights: the case against animals. Oxford: Clarendon Press.

[48] Peabody, F.W. (1928). The soul of the clinic. Journal of the American Medical Association 88, 877-882.

[49] Loughlin, M. (2010). Epistemology, Biology and Mysticism. Journal of Evaluation in Clinical Practice 16 (2) 298-300.

[50] Dupré, J. (2002). Humans and other Animals. Oxford: Oxford University Press.

[51] Ryan, T. (2011). Animals and Social Work: a moral introduction. Basingstoke: Palgrave.

[52] Hursthouse, R. (2000). Ethics, Humans and other Animals. London: Routlege.

[53] Clark, S.R.L. (1984). The Nature of the Beast. Oxford: OUP.

[54] Hutchinson, P. (2008). Shame and Philosophy: an investigation in the philosophy of emotion and ethics. Basingstoke: Palgrave.

[55] Hamilton, R. (2010). The concept of health: beyond normativism and naturalism. Journal of Evaluation in Clinical Practice 16 (2) 323-329. 